\title{
Farmland preservation policies in China and their impacts on urban expansion: a multilevel analysis
}

DOI:

10.1080/09640568.2021.1876000

\section{Document Version}

Accepted author manuscript

Link to publication record in Manchester Research Explorer

\section{Citation for published version (APA):}

Zhong, T., Zheng, W., Zhao, Y., Zhang, Y., \& Huang, X. (2021). Farmland preservation policies in China and their impacts on urban expansion: a multilevel analysis. Journal of Environmental Planning and Management. https://doi.org/10.1080/09640568.2021.1876000

\section{Published in:}

Journal of Environmental Planning and Management

\section{Citing this paper}

Please note that where the full-text provided on Manchester Research Explorer is the Author Accepted Manuscript or Proof version this may differ from the final Published version. If citing, it is advised that you check and use the publisher's definitive version.

\section{General rights}

Copyright and moral rights for the publications made accessible in the Research Explorer are retained by the authors and/or other copyright owners and it is a condition of accessing publications that users recognise and abide by the legal requirements associated with these rights.

\section{Takedown policy}

If you believe that this document breaches copyright please refer to the University of Manchester's Takedown Procedures [http://man.ac.uk/04Y6Bo] or contact uml.scholarlycommunications@manchester.ac.uk providing relevant details, so we can investigate your claim.

\section{OPEN ACCESS}




\title{
Farmland preservation policies in China and their impacts on urban expansion: A multilevel analysis
}

Taiyang Zhonga, Wei Zheng ${ }^{\mathrm{b}}$, Yuntai Zhao ${ }^{\mathrm{c}}$, Yu Zhang ${ }^{\mathrm{d}}$, Xianjin Huang ${ }^{\mathrm{e}}$

a. School of Geography and Ocean Science, Nanjing University, 163 Xianlin Avenue, Nanjing, Jiangsu Province, China 210023, taiyangzhong@163.com

b. Department of Planning and Environmental Management, Manchester Urban Institute, The University of Manchester, Manchester M13 9PL, UK, helen.zheng@manchester.ac.uk

c. China Land Surveying and Planning Institute, 37 West Guanyingyuan, Beijing, China 100035, andy_striving@163.com

d. School of Geography and Ocean Science, Nanjing University, 163 Xianlin Avenue, Nanjing, Jiangsu Province, China 210023, yuzhangnju18@163.com

e. School of Geography and Ocean Science, Nanjing University, 163 Xianlin Avenue, Nanjing, Jiangsu Province, China 210023, hxj369@nju.edu.cn

\begin{abstract}
There has been limited research examining the impact of the top-down and quota-oriented farmland preservation policies on urban land expansion at the city level in China. This paper aims to narrow this gap, particularly focusing on the policies of prime farmland preservation quota and farmland conversion quota. A multilevel modelling approach was applied to examine the effects. The findings suggest that the two policies had limited effects. The limited effect of the two policies are rooted in the gaps between planning policy making and implementation. Specifically, prefecture-level city-biased allocation of conversion and preservation quotas led to less restrictions on prefecture-level cities. The decoupling of annual quotas and land use planned quotas undermined the controlling effects on urban land expansion. There also existed inconsistent farmland conversion quota being incorporated into new plans. Additionally, the insufficient capacity of monitoring policy implementation, especially for prime farmland use, strongly weakened the potential effects.
\end{abstract}


Keywords: Plan implementation evaluation; farmland protection; land use planning; urban growth management; China

\section{Introduction}

There is no consensus on the impact of farmland preservation policies on urban expansion. Since numerous studies have revealed that urban expansion consumes a large amount of farmland around the world (Seto et al. 2011), farmland protection policies have been proposed to prevent urban expansion over farmland in China (Zhao 2011). Empirical research has demonstrated that farmland preservation policies can reduce the hazards of developing protected farmlands (Huang et al. 2015), and mitigate rampant urban expansion (Luo and Wei 2009). There are, however, some contradictory findings in different contexts regarding the effects of farmland protection policies on urban expansion (Yue, Liu, and Fan 2013). This calls for a more comprehensive understanding of the underlying relationships between farmland protection policies and urban expansion from aggregated evidences at the larger spatial scale.

China has a top-down land planning and administration system with national government providing the guideline for land use planning and other lower-level governments ${ }^{1}$ conforming to their higher-level government planning (Zhong et al. 2017). Farmland protection policies, embedded in China's top-down land use planning system, have long been used to control urban expansion (Zhao 2011). Since the 1990s, China's central government has attempted to protect farmland and control nonagricultural land growth by implementing top-down land use planning (Zhong et al. 2017). China's State Council approved the National General Land Use Plan (1997-2010) in 1999, referred to as the 'National 1997-2010 Plan' in this paper. The plan is characterized by top-down, quota-oriented, and farmland protection-centered features. A series of land use planning quotas were hierarchically decomposed to the countylevel areas and even to the township-level administrative regions, which are interpreted as land use restrictions by means of land use zones (Chau and Zhang 2011). These quotas involve the quota of farmland conversion to non-agricultural use, prime farmland preservation, and newly added farmland.

Despite the unique and significant role of the quota policy for farmland preservation in China, there remains a limited understanding of its impact on the expansion of urban land. Several research gaps are identified from previous studies. First, previous studies mainly focus on a zoning-based farmland preservation system in western contexts rather than the top-down quota-oriented planning system that is

\footnotetext{
1 There are five-level governments in China including national, provincial, prefectural, county and township levels.
} 
unique in China. Second, there are two main types of quota for farmland preservation in the National 1997-2010 Plan. One is the prime farmland preservation quota ('preservation quota') which aims to preserve good-quality farmland from development, and the other is the quota for farmland conversion to non-agricultural use ('conversion quota') which aims to control existing farmland loss. Few studies, however, have compared various land use policy tools in terms of the effectiveness in controlling urban expansion in China. Going beyond existing research, this paper examines both quota policies. Third, little attention has been paid to the influence of the intensity of farmland protection policies on urban expansion; the majority of studies generally adopted the method of using a dummy variable to express whether farmland protection is in place, with a few exceptions discussing the measure of policy intensity and its meaning for urban growth (Paulsen 2013). Furthermore, the arguments of existing literature are made in light of different empirical studies at small scales (e.g. a city). Nevertheless, a macro-level analysis on the impact of farmland preservation policies embedded in the national planning system on urban expansion, which can shed light on strategic spatial planning, is still limited. This paper thus examines the impact of the farmland preservation policies reflected by planned quotas in the top-down land use plans with the horizon of 1997-2010 on urban expansion by utilizing the large-scale data of prefecture-level and above prefecture-level cities in China. The following questions are explored: (1) Do 'preservation quota' and 'conversion quota' in land use plans with the horizon of 1997-2010 reduce urban expansion? (2) To what extent does the intensity of the farmland preservation policy matter? The paper first provides a brief introduction to existing literature on farmland protection policy tools and China's main policies of farmland preservation, followed by a presentation of the data and methodology, then the results and discussions, and finally the conclusions.

\section{Farmland protection policy and urban expansion}

\subsection{Farmland protection policy tools}

Protection of agricultural land, as an important planning goal in many countries (e.g. Netherlands, Germany, Japan, and the US), is also a crucial urban containment strategy (Millward 2006). There have been two main strands of research on various policy tools for farmland protection. The first strand of research is rooted in regulatorybased farmland protection policies such as zoning policy. Zoning tools for farmland protection have been widely used in many different countries including agricultural land reserves in Canada (Leo and Anderson 2006) as well as agricultural protection zoning and agricultural conservation districts in USA (Jerry 2004). This kind of agricultural zoning involves restrictions on a specific area in which development is permanently prohibited (Vyn 2012). It is the most common used approach to 
prohibiting the development on agricultural land (Coughlin 1991). Overall, existing empirical research provides mixed findings regarding the effectiveness of zoning in mitigating urban sprawl and protecting forest and farmland (Bengston, Fletcher, and Nelson 2004; York and Munroe 2010). The second strand of research has focused on the market-based policy tools; for example, Purchase of Development Rights (PDR) is an important tool for farmland preservation in the US (Towe, Nickerson, and Bockstael 2008; Brinkley 2012). Via the purchase or voluntary donation of development rights from willing landowners, an agricultural conservation easement (ACE) is established on the property that restricts the amount and types of development that can occur. Permitted uses for an agricultural conservation easement typically involve any agricultural use, relevant structures, and open space (Daniels 2020). Though most easements are permanent, a small proportion last for a specific period such as a 30-year term (ibid). Geographical targeting of ACEs has been accepted as an effective policy tool for curbing growth (York and Munroe 2010). Land trusts, as bottom-up, private, and non-profit organizations in the USA, play a significant role in protecting farmland via ACEs; the main argument underlining their actions is that the rationale of protecting farmland is not only rooted in its economic value, but also social and cultural values (Brinkley, 2012). In the Chinese context, the development allowance policy is adopted as a market-based policy tool to realize transferable development rights. It was found to increase newly cultivated land driven by urban expansion forces, whereby an allowance of farmland conversion quota is obtained in proportion to the amount of newly-added farmland through land consolidation (Chau and Zhang 2011).

\subsection{Land use planning quota in China and its potential influence on urban expansion}

China's land-use planning is characterized by its hierarchical and top-down system. There are five levels of governments in China, including national, provincial, prefectural, county and township levels. Within this system, there are four administrative levels of cities in China, including directly-administered municipalities under the central government (also called provincial-level city, e.g. Beijing and Shanghai), sub-provincial cities (e.g. Nanjing, Shenzhen, and Wuhan), prefectural-level cities ${ }^{2}$, and county-level cities ${ }^{3}$ (NBS 2002-2012). National planning provides the guideline for land use planning at other lower levels including province, prefecture, county and township; planning by lower-level governments must conform to their higher-level government planning (Zhou et al. 2017). Since the 1990s China's central government has introduced strict farmland protection policies in response to rapid farmland loss (Long 2014). It was estimated that farmland was the

\footnotetext{
2 A prefectural-level city in China is a prefectural-level administrative unit (region), which commonly comprises of central urban area (where the prefectural-level government is located), and subordinate counties or county-level cities.

${ }^{3}$ A county-level city is a county-level administrative unit, which comprises of central urban area of the county (where the county-level government is located), and several township-level administrative units.
} 
major land source for Chinese urban expansion between 1990 and 2010, with about 63\% of urban and industrial land expansion happening on farmland (Kuang et al. 2016). The failure of urban planning in controlling urban expansion in the late 1990s led to the strengthening of the land authority, which has been expected to provide effective development control as well as agricultural land protection (Wu 2015). The Land Administration Law was amended in 1998, proposing two fundamental policies of farmland protection in the 1999 Land Administration Law. One is the prime farmland preservation policy that allows no conversion to non-agricultural use without permission from the State Council (SC 1998). Farmland that is not designated as prime farmland is called ordinary farmland (Zhong et al. 2017). Any conversion of less than 35 ha of ordinary farmland needs permission from the provincial-level government, or else from the State Council (SCNPC 1998). Unlike ordinary farmland, any conversion of prime farmland to non-agricultural use must obtain approval from the State Council. Prime farmland is mainly used for food crop, and it is prohibited for fish-farming ponds as well as planting trees and lawn. Generally, prime farmland has better soil quality and access to transport and irrigation facilities (Zhong et al. 2017). Another policy is the "dynamic balance" policy, which requires no net loss of farmland within a provincial region. Particularly, the 1998 Land Administration Law requires replacing farmland converted to non-agricultural use with the same amount of newly-added farmland (SCNPC 1998).

Land use planning adopts two types of quotas to determine the amount of farmland conversion to non-agricultural use and prime farmland preservation, that is, the conversion quota and the prime farmland preservation (PFP) quota. The quotas of prime farmland preservation (preservation quota) and farmland conversion to non-agricultural use (conversion quota) were handed down to the county-level and even township-level regions. The National 1997-2010 Plan set a preservation goal of 108.6 million ha of prime farmland, accounting for $83.5 \%$ of farmland in 1996 (SC 1999). The amount of prime farmland in a plan was required to be no less than the quota assigned by its higher level general land-use plan (SCNPC 1998). There have been some studies at the city level indicating that the prime farmland preservation policy reduced urban expansion or farmland loss in different Chinese cities (Huang et al., 2015). The conversion quota in the general land use plan sets a cap for farmland conversion to non-agricultural use within the planning horizon. The National 1997-2010 Plan set a cap of no more than 2 million ha of farmland to be converted to non-agricultural use from 1997 to 2010 (SC 1999). To convert farmland to non-agricultural use, local governments need to obtain permission from central and provincial governments in the top-down land use administrative system (Zhong et al. 2017). The quota of farmland conversion is a primary reference for central and provincial governments when evaluating local governments' applications for farmland conversion to non-agricultural use. Motivated 
by land revenues, local governments attempt to obtain as large as possible quotas of land conversion to non-agricultural use (Yang and Wang 2008).

With these above-mentioned regulations, the policy of farmland protection placed strict restrictions on the expansion of urban land (Zhao 2011). It was estimated that farmland contributed to 53\% of the built-up land expansion in China from 1991 to 2008 (Li 2011). Most cities were historically located in proximity to agricultural land (Martellozzo et al. 2015). Theoretically, the effort to preserve farmland by limiting farmland conversion to non-agricultural use through the farmland conversion quota scheme would therefore restrict urban expansion. The less stringent the restrictions imposed by the farmland conversion quota, the larger the urban expansion is expected to be. Furthermore, the Prime Farmland Protection Regulation requires that farmland located within urban and town peripheries, as well as alongside railways and highways, must be preferentially designated as prime farmland (SC 1998), whilst the periphery of Chinese cities is usually close to agricultural land (Angel, Parent, and Civco 2012). Hence, the prime farmland preservation policy could make a difference in reducing the land provision for urban development if implemented strictly; although it does not directly delineate a boundary for restricting urban expansion.

\section{Data and Methods}

This study aims to examine whether the policy of prime farmland preservation quota and the policy of farmland conversion quota have controlled urban land expansion by using evidence from prefecture-level and above prefecture-level cities in China. The urban expansion in this study refers to the expansion of center urban area of prefecture-level and above prefecture-level cities. Most general land use plans at the provincial level with the horizon of 1997-2010 were approved by the State Council in 1999 and their associated prefectural-level plans were subsequently approved, in 2000. This study thus investigates the impact on urban expansion of farmland preservation policy embedded in land use planning from 2000 to 2010. Data from multiple sources were integrated for use in multilevel modelling analyses.

\subsection{Dependent variable and independent variables}

\subsubsection{Dependent variable}

When it comes to urban expansion, the size of urban land area or urbanized area and the changes in their sizes could be used to measure the extent of urban land development (Paulsen 2013). Therefore, the change in urban land area, symbolized as $D U L$, is used as the dependent variable in this study to measure urban expansion over time, whose value is equal to the variation of urban land areas between two time points. 


\subsubsection{Variables for preservation and conversion quotas}

The policies of interest include the PFP quota and the conversion quota. The PFP policy, reflected by the preservation quota in land use plans with the horizon of 19972010, is expected to have a negative effect on urban land expansion in China. Due to the difference in the total area of farmland for each city, the same number of preservation quotas does not mean the same strictness of prime farmland preservation. The preservation ratio (the ratio of preservation quota to total farmland area) is an appropriate measurement to calculate the intensity of prime farmland preservation. However, during the planning horizon of 1997 to 2010, some regions were assigned the quota of 'Grain for Green' (Zhong et al. 2017), which aimed to convert some farmland to forest use for a better environment. This would cause the phenomenon in which two cities have the same preservation ratio but possess noticeable differences in their de facto intensities of the prime farmland preservation policy when the quota of Grain for Green is not allocated in proportion to the total farmland area. Hence, the real preservation ratio (symbolized as $I P Q$ ) was used in this study, which was calculated as the ratio of preservation quota to the difference between the total farmland area and the quota of Grain for Green. The variable $I P Q$ thus reflects the intensity of prime farmland preservation and a higher indicates a higher intensity of the preservation quota policy and stricter restrictions on farmland conversion to other uses.

Like the quota of prime farmland preservation, the conversion quota per se cannot measure the intensity of the conversion quota policy. The intensity could be measured as the ratio of the demand to supply of land for urban development. The conversion quota can be viewed as planned urban land supply. Unfortunately, there is no direct way to measure the actual demand of land for urban development. Some empirical studies have indicated that the demand of land for urban development is positively correlated with its previous demand (Woo and Guldmann 2014). Therefore, the demand of land for urban development in the period from 2000 to 2010 can be viewed as a function of the demand of land for urban development in the period from 1990 to 2000. The change in urban land area in the period from 1990 to 2000 can be regarded as the proxy of the demand of urban development in the period from 2000 to 2010. The variable $I C Q$ was employed to represent the intensity of conversion quota policy, whose value was calculated by dividing the change in urban land area in the period from 1990 to 2000 by the conversion quota. The larger the value of the variable ICQ is, the stricter the conversion quota policy imposes restrictions on urban expansion. The variable ICQ is thus expected to have a negative coefficient, which suggests the policy of the conversion quota did decrease urban land expansion. 


\subsubsection{Other independent variables}

Many economic factors influence urban land expansion besides government policies. First, economic growth has been corroborated as an influential factor for China's urban land expansion (Seto, Güneralp, \& Hutyra, 2012). The growth of GDP is commonly used to reflect economic growth (Bai, Chen, and Shi 2012). However, there is a relatively high correlation coefficient between the variable ICQ and GDP (over 0.4). To overcome this issue, an alternative variable, investment, was considered. Economic growth is greatly driven by investment and some studies have shown that investment has played a role in prompting urban expansion, such as foreign direct investment (Gao et al. 2014) and fixed-assets investment (Peng et al. 2015). Thus, the variable ACINV was used to represent the accumulative amount of fixed-asset investment for the period from 2000 to 2010. Economic structure (industry composition) is another factor influencing farmland conversion to non-agricultural use. Built-up land in a city with a higher share of GDP for the secondary industry expands faster (Deng et al. 2010). Additionally, industry structure such as the share of the secondary industry in economy always influence governments' behaviors in urban land management ( $\mathrm{Lu}$ and Wang 2020b). Hence, the variable SECON was used to capture the economic structure of a region, whose value is the share of the city's total GDP for the secondary industry in 2000. Land price also greatly influences urban land market and urban land expansion (Jaeger 2013). The variable LPRICE was thus used to measure the price of urban land, whose value is equal to land transaction price per unit area.

Second, population growth has been regarded as another key driving factor of urban land expansion (Wu and Zhang 2012). The variable CPOP was adopted as an independent variable to reflect the change in urban population, and it is expected to have a positive coefficient.

Third, there are some physical limitations to urban land supply, which are commonly reflected by geophysical factors including slope and the share of plain or flat land (Deng et al. 2010). Based on the study by Deng et al. (2010), the variable SFLAT in this study was denoted as the proportion of the land with a slope less than eight degrees within a prefecture-level administrative region. A higher value of the variable SFLAT usually means lower difficulty in land development; thus the variable SFLAT is expected to have a positive coefficient.

Fourth, some factors related to urban density could also influence urban land expansion. Some cities were given a requirement of urban land per capita by land use plans. The urban land per capita in land use plans essentially sets upper limits or lower limits for urban population density. The dummy variable DENULL was used to represent whether there is a policy of urban land per capita in land use plans. The cities with such a policy could be more likely to place emphasis on land use efficiency and 
controlling urban land expansion, the variable DENULL (for cities without such a policy, $D E N U L L=1$ ) is therefore expected to have a positive coefficient. The variable CONSP was used to represent urban land per capita. A city with higher urban land per capita would have a larger demand for urban land and the variable CONSP is assumed to have a positive coefficient.

Fifth, the political status of cities is also an influential factor for construction land expansion in China (Lu and Wang 2020a). Administrative rank has been adopted to reflect cities' political status ( $\mathrm{Li}$ et al. 2015). There are provincial, sub-provincial, prefectural, and county-level cities in China. Provincial and sub-provincial level cities have higher political and economic influence than prefectural and county-level cities. Provincial and sub-provincial level cities commonly have advantages in urban land development ( $\mathrm{Li}$ et al. 2015). Besides, capital cities in different provinces possess advantages in the allocation of land development quotas. Hence, three variables were generated to interpret cities' political status. The variable POLISTA was used to show whether a city is a provincial capital, a provincial city, or a sub-provincial city. The variable $P R O V C$ was applied to express whether a city is a provincial capital. The variable $S U B P R$ was used to represent whether a city is a sub-provincial city.

Sixth, the provincial-level regions are traditionally grouped into three economic regions, including East, Middle and West (Zhou et al. 2017); this classification can reflect traditional geographical differences in China which may be related to urban land expansion. Two dummy variables, RESAT and RMIDD, were generated to represent the East and Middle, respectively.

Apart from the two dummy variables representing province-level regions, another two variables at the provincial level were used as contextual variables, including $M C P O P$ and MACINV. The values of the two variables were aggregated from the city-level data, which can reflect the situation of population change and investment at the provincial level. In the multi-level modelling, it is common to derive contextual variables at the level two by using the cluster means of the level-one variables (Rabe-Hesketh and Skrondal 2012). The variable $M C P O P$ represents average population growth of cities in different provinces (calculated as the mean value of $C P O P$ ) and the variable $M A C I N V$ stands for average investment of cities in various provinces (calculated as the mean value of $A C I N V$ ). As the investment measured at the provincial level has been proved to contribute to urban land expansion at the city-level (Jiang, Deng, and Seto 2012), MACINV and MCPOP are assumed to have positive coefficients. Table 1 shows the definitions of different variables and their assumed signs of coefficients. Table 2 provides summary statistics of these variables.

Table 1 Dependent and independent variables used in the study 


\begin{tabular}{|c|c|c|}
\hline Variable & Definition & $\begin{array}{l}\text { Expected sign } \\
\text { for coefficient }\end{array}$ \\
\hline$D U L$ & $\begin{array}{l}\text { Dependent variable: change in urban land area }\left(\mathrm{km}^{2}\right) \\
\text { Level-1 (city-level) variables }\end{array}$ & \\
\hline$I C Q$ & $\begin{array}{l}\text { Intensity of conversion quota policy: ratio of the change } \\
\text { in urban land area in the period from } 1990 \text { to } 2000 \text { to the } \\
\text { conversion quota }\end{array}$ & - \\
\hline$I P Q$ & $\begin{array}{l}\text { Intensity of preservation quota policy: the ratio of } \\
\text { preservation quota the total farmland area in the planning } \\
\text { base year deducting the quota for Grain for Green policy } \\
(\%)\end{array}$ & - \\
\hline$A C I N V$ & $\begin{array}{l}\text { Investment: the accumulative amount of fixed-asset } \\
\text { investment for a period }\left(10^{8} \text { yuan }\right)\end{array}$ & + \\
\hline СРОР & $\begin{array}{l}\text { Population growth: The change in urban population }\left(10^{4}\right. \\
\text { persons) }\end{array}$ & + \\
\hline SECON & $\begin{array}{l}\text { Industry composition: the share of GDP for the secondary } \\
\text { industry in } 2000(\%)\end{array}$ & + \\
\hline SFLAT & $\begin{array}{l}\text { Physical limitation: The proportion of the land with slop } \\
\text { less than eight degree to a prefecture-level administrative } \\
\text { region }(\%)\end{array}$ & + \\
\hline DENULL & $\begin{array}{l}\text { Land use intensity policy: } D E N U L L=1 \text { for those cities } \\
\text { without lower-limit policy of urban land per capita in } \\
\text { land use plans, } 0 \text { for otherwise }\end{array}$ & + \\
\hline CONSP & $\begin{array}{l}\text { Urban land per capita: Area of urban construction land } \\
\text { per } 10,000 \text { people in } 2000\left(\mathrm{~km}^{2}\right)\end{array}$ & + \\
\hline POLISTA & $\begin{array}{l}\text { Political status: POLISTA=1 for cities which are } \\
\text { provincial capital, provincial or sub-provincial city, } 0 \text { for } \\
\text { otherwise }\end{array}$ & + \\
\hline PROVC & $\begin{array}{l}\text { Provincial capital: } P O L I S T A=1 \text { for cities which are } \\
\text { provincial capital, } 0 \text { for otherwise }\end{array}$ & + \\
\hline
\end{tabular}




\begin{tabular}{llc}
\hline SUBPR & $\begin{array}{l}\text { Sub-provincial city: } S U B P R=1 \text { for cities which are sub- } \\
\text { provincial city, } 0 \text { for otherwise }\end{array}$ & + \\
LPRICE & Urban land price $\left(10^{4}\right.$ Yuan/ha) & + Level-2 (province-level) variables \\
REAST & East regions: $R E A S T=1$ for cities located within East and & + \\
& 0 for otherwise & + \\
RMIDD & Mid regions: $R M I D D=1$ for cities located within Middle & + \\
and 0 for otherwise & + \\
MACINV & Mean of $C P O P\left(10^{4}\right.$ persons $)$ & + \\
\hline
\end{tabular}

Note: 1 USD is about 7 Yuan 
Table 2 Summary statistics of the variables used in the study

\begin{tabular}{|c|c|c|c|c|c|c|}
\hline Level & Variable & $\mathrm{N}$ & Mean & Std. Dev. & Min & $\operatorname{Max}$ \\
\hline \multirow{13}{*}{ City level } & $D U L$ & 229 & 180.206 & 257.005 & 8.500 & 1749.200 \\
\hline & $I C Q$ & 229 & 1.113 & 2.3690 & 0.010 & 30.555 \\
\hline & $I P Q$ & 229 & 86.324 & 5.501 & 40.000 & 99.6890 \\
\hline & $A C I N V$ & 226 & 2211.175 & 3887.184 & 119.150 & 31529.230 \\
\hline & СРОР & 229 & 73.390 & 92.219 & -288.480 & 633.620 \\
\hline & SECON & 229 & 49.711 & 12.774 & 15.000 & 92.300 \\
\hline & SFLAT & 229 & 67.394 & 24.6890 & 8.420 & 100.000 \\
\hline & DENULL & 229 & 0.336 & 0.474 & 0.000 & 1.000 \\
\hline & CONSP & 229 & 1.1443 & 0.775 & 0.100 & 5.210 \\
\hline & POLISTA & 229 & 0.144 & 0.352 & 0.000 & 1.000 \\
\hline & PROVC & 229 & 0.122 & 0.328 & 0.000 & 1.000 \\
\hline & $S U B P R$ & 229 & 0.066 & 0.248 & 0.000 & 1.000 \\
\hline & LPRICE & 229 & 365.828 & 225.406 & 37.78 & 1452.020 \\
\hline \multirow{4}{*}{$\begin{array}{l}\text { Provincia } \\
\text { l level }\end{array}$} & $R E A S T$ & 229 & 0.402 & 0.491 & 0.000 & 1.000 \\
\hline & $R M I D D$ & 229 & 0.345 & 0.476 & 0.000 & 1.000 \\
\hline & МСРОР & 229 & 73.390 & 69.780 & 15.325 & 633.620 \\
\hline & MACINV & 229 & 2199.275 & 3102.261 & 669.443 & 31529.230 \\
\hline
\end{tabular}




\subsection{Data sources}

The data regarding planning quotas were collected and computed from a collection of plans called National General Land Use Planning: 1997-2010 (Lu 2001). Three volumes were used, including the National 1997-2010 Plan, 31 provincial-level general land use plans, and 80 prefecture-level plans with the horizon of 1997-2010. The data of the quotas for PFP, farmland conversion to non-agricultural use, and GFG were extracted from the abovementioned plans. The data on urban expansion were collected from the Atlas for Remote Sensing of Urban Expansion of Prefecture-level and Above Prefecture-level Cities in China (China Land Surveying and Planning Institute and Twenty First Centuary Aerospace Technology Co. 2015). Economic and demographic data were gathered from the China City Statistical Yearbook (NBS 2002-2012). The values of the variables relating to the economy were inflation-adjusted. The data on slope and elevation were generated from China's digital elevation model dataset, which is provided by the Data Center for Resources and Environmental Sciences, Chinese Academy of Sciences (RESDC) ${ }^{4}$.

\subsection{Empirical model}

The OLS and multilevel models were used in this study. The data of urban expansion associated with the plan implementation are multilevel as the cities are nested in provinces. Given the hierarchical structure of the data, it is reasonable to use a multilevel modelling approach to perform analysis. There are random-intercept and random-slope models for the multi-level models (Rabe-Hesketh and Skrondal 2012). Due to the issue of convergence caused by the data structure and small sample size, it is not reasonable to incorporate random slopes in the multi-level models (Overmars and Verburg 2006). Thus, this study adopted the random-intercept models. The two-level models were used: (1) the level-2 variables which vary at the provincial level, include the variable RESAT, RMIDD, MCPOP and MACINV; (2) the level-1 variables, which vary at the city level, involve the rest variables in Table 1 except the variable RESAT, RMIDD, MCPOP and MACINV. For city $j$, and province $k$, the reduced form of the two-level model goes as follows:

$$
\begin{aligned}
& D U L_{j k}=\alpha_{0}+\beta_{1} \text { REAST }_{k}+\beta_{2} \text { RMIDD }_{k}+\beta_{3} \text { MCPOP }_{k}+\beta_{4} \text { MACINV }_{k}+\lambda_{1} I P Q_{j k}+\lambda_{2} I C Q_{j k}+\lambda_{3} \text { CPOP }_{j k}+ \\
& \lambda_{4} \text { ACINV }_{j k}+\lambda_{5} \text { SECON }_{j k}+\lambda_{6} \text { SFLAT }_{j k}+\lambda_{7} \text { DENULL }_{j k}+\lambda_{8} \operatorname{CONSP}_{j k}+\lambda_{9} \text { POLIST }_{j k}+\lambda_{10} \text { PROVC }_{j k}+ \\
& \lambda_{11} \text { SUBPR }_{j k}+\lambda_{12} \text { LPRICE }_{j k}+\zeta_{k}+\varepsilon_{j k}
\end{aligned}
$$

\footnotetext{
${ }^{4}$ Which is available at http://www.resdc.cn.
} 
Where, $\alpha_{0}$ is the intercept; $\zeta_{k}$ is the province-level random intercept and assumed to have

zero mean and variance $\theta_{2}^{2}, \varepsilon_{j k}$ is the city-level error term and assumed to have zero mean and variance $\theta_{1}^{2} ; \beta$ and $\lambda$ are the coefficients for the province-level and city-level variables, respectively.

The variables $C P O P$ and $A C I N V$ were not included in one model simultaneously. First, investment (represented by the variable $A C I N V$ ) is the proximate driving factor of urban land development while urban population growth (represented by the variable $C P O P$ ) is a direct driving factor. Thus, $A C I N V$ can be used as an alternative for $C P O P$. Second, the correlation coefficient between the variable $C P O P$ and the variable $A C I N V$ is 0.801 which could cause the issue of multicollinearity.

Furthermore, the correlation coefficient between the variable POLISTA and the variable $A C I N V$ is about $0.7(0.683)$, whilst that between the variable $S U B P R$ and the variable $A C I N V$ is higher than 0.6. Therefore, POLISTA, PROVC and SUBPR were not included in the models that include $A C I N V$ to avoid the multicollinearity issue. Similarly, the correlation coefficient between LPRICE and POLISTA is 0.576, and that between LPRICE and ACINV is 0.632. Hence, LPRICE was not included in the models with POLISTA. Therefore, five models with different sets of variables were established beyond the Null model to show the effects from different variables (see Table 3).

\section{Model Fitting Results}

Table 3 presents the estimation results from multilevel models. The null model (represented as $\mathrm{N}$ in the Table 3) is listed in the last column of Table 3. Both model P1 and model P2 include variables representing urban population change (CPOP and $M C P O P)$ and political status of cities. The model P1 includes the variable POLISTA while the POLISTA is replaced by the two variables $P R O V C$ and $S U B P R$ in the model P2. The model I1 and model I2 include variables representing investment (variable ACINV and MACINV) instead of urban population change. The model $\mathrm{I} 2$ is a nested model of I1. As the correlation coefficient between LPRICE and POLISTA is 0.576, and that between LPRICE and POLISTA is 0.632, another model LP was estimated, where the variable POLISTA in Model P1 was replaced by the variable $L P R I C E$.

\begin{tabular}{l|llllllll}
\hline Level & Variable & P1 & P2 & I1 & I2 & LP & N \\
\hline
\end{tabular}




\begin{tabular}{|c|c|c|c|c|c|c|c|}
\hline \multirow{12}{*}{ City level } & $I P Q$ & $-3.731^{* *}$ & $-3.986^{* *}$ & $-3.275^{* *}$ & $-3.564^{* *}$ & $-3.867^{* * *}$ & \\
\hline & $I C Q$ & $-9.649^{* *}$ & $-9.039^{* *}$ & $-7.181^{*}$ & $-6.646^{*}$ & $-9.343^{* *}$ & \\
\hline & СРOP & $1.411^{* * *}$ & $1.337^{* * * *}$ & & & $1.582^{* * * *}$ & \\
\hline & $A C I N V$ & & & $0.046^{* * *}$ & $0.046^{* * * *}$ & & \\
\hline & POLISTA & $118.119^{* * *}$ & & & & & \\
\hline & PROVC & & $95.834^{* * *}$ & & & & \\
\hline & $S U B P R$ & & $96.776^{* *}$ & & & & \\
\hline & SECON & $1.145^{*}$ & $1.181^{*}$ & 0.184 & & 0.862 & \\
\hline & CONSP & $43.887^{* * *}$ & $47.158^{* * *}$ & $73.156^{* * *}$ & $79.663^{* * *}$ & $37.540^{* * *}$ & \\
\hline & SFLAT & $0.905^{* *}$ & $0.850^{* *}$ & 0.347 & & $1.160^{* *}$ & \\
\hline & DENULL & -59.549 & -53.659 & -11.463 & & $-63.461^{*}$ & \\
\hline & LPRICE & & & & & $0.127^{* *}$ & \\
\hline \multirow{9}{*}{$\begin{array}{l}\text { Provincial } \\
\text { level }\end{array}$} & МСРОР & $0.686^{* * *}$ & $0.810^{* * * *}$ & & & $0.566^{*}$ & \\
\hline & $M A C I N V$ & & & 0.008 & $0.010^{* *}$ & & \\
\hline & $R E A S T$ & $144.429^{* *}$ & $140.395^{* *}$ & 62.412 & & $105.249^{*}$ & \\
\hline & $R M I D D$ & 18.492 & 17.844 & -7.910 & & -0.793 & \\
\hline & constant & 132.258 & 148.798 & 213.448 & 272.387 & 139.794 & $288.156^{* * *}$ \\
\hline & var(_cons & 14757.940 & 15559.140 & 4972.825 & 5682.856 & 13739.170 & 161597.800 \\
\hline & $\begin{array}{l}\operatorname{var}(\text { Resid } \\
\text { ual) }\end{array}$ & 14116.010 & 13592.490 & 13939.860 & 14021.050 & 14900.850 & 30435.660 \\
\hline & $\begin{array}{l}\text { LR test } \\
\text { chi }^{2}\end{array}$ & $28.300^{* * *}$ & $29.070^{* * * *}$ & $22.970^{* * *}$ & $31.760^{* * * *}$ & $23.720^{* * *}$ & $76.190^{* * *}$ \\
\hline & $\mathrm{N}$ of obs & 229 & 229 & 226 & 226 & 229 & 229 \\
\hline
\end{tabular}




\begin{tabular}{|c|c|c|c|c|c|c|}
\hline $\begin{array}{l}\mathrm{N} \text { of } \\
\text { groups }\end{array}$ & 29 & 29 & 29 & 29 & 29 & 29 \\
\hline Wald chi ${ }^{2}$ & $421.260^{* * * *}$ & $434.430^{* * * *}$ & $559.300^{* * *}$ & $538.590^{* * * *}$ & $402.280^{* * * *}$ & \\
\hline $\begin{array}{l}\text { Log } \\
\text { likelihood }\end{array}$ & -1447.960 & -1444.719 & -1416.239 & -1418.114 & -1452.675 & -1557.086 \\
\hline AIC & 2919.919 & 2915.437 & 2854.478 & 2848.228 & 2929.349 & 3116.171 \\
\hline BIC & 2961.124 & 2960.075 & 2892.104 & 2868.751 & 2970.554 & 3119.605 \\
\hline
\end{tabular}

64

The estimated results of the null model show the contribution of differences between provinces to the total variance. The estimated between-province (level-2) variance of the null model is 161597.800 and the between-city variance within the province is 30435.660 . The variance partition coefficient (VPC) is $161597.800 /(161597.800+30435.660)=0.842$, which indicates that about 84 percent of the variance in urban expansion can be attributed to differences between provinces. The likelihood ratio test statistic is 76.190 with a p-value of 0 , which indicates that provincial effects are significant, and the multilevel model is superior to the single-level model. Adding variables substantially decreased level-1 and level-2 variance. Compared with the null model, the estimation results of the five full models of P1, P2, I1, I2 and LP indicate that the total variance decreased by $84.964 \%, 84.820 \%, 90.151 \%, 89.739 \%$ and $85.086 \%$, respectively, which indicates that the covariates can explain most of the variance.

Apart from a larger magnitude of total variance decrease, the AIC and BIC values for the estimated models of I1 and I2 are smaller than those for P1, P2, and LP, which suggests that I1 and $\mathrm{I} 2$ are superior to P1, P2 and LP. Both the AIC and BIC values for the estimated model $\mathrm{I} 2$ are the lowest, which indicates that $\mathrm{I} 2$ is the most preferred model among these five models. As P1 and P2 include variables different from I1 and I2, the estimation results of P1 and P2 are also meaningful for understanding urban spatial expansion. Compared with $\mathrm{P} 1$, the model P2 has smaller values of AIC and BIC. Hence, the estimation results of model P2 and I2 will be mainly used to analyze the impacts of independent variables in the following sections. 


\section{Results and Discussions}

\subsection{Impacts from control variables}

The model P2 shows that cities' political status (reflected by PROVC and SUBPR) delivered a positive effect on urban land expansion. In the model P2, expected effects were also observed from the estimated coefficients of SECON, CONSP and SFLAT. There were no significant effects from the variable $R M I D D$ in all the models. REAST showed significantly positive effects (P1 and P2 in Table 3), suggesting the great influence from cities' land use demand and the market force. Relatively, cities in the east of China have been more developed with better accessibility, thus being able to attract more investment for development. They are in dire need of land resources. Though western cities in China have long been regarded as the least developed cities compared with those in the middle and in the east, there were no significant effects on urban land use change from whether they are located in the middle or in the west. This may be explained by the variety of cities in the west and middle. The coefficient of DENULL was significant at the $10 \%$ level in the model LP $(p=0.094)$ while it did not show significant effects in other four models. The policy of lower-limit urban land per capita was integrated into about $66.380 \%$ of prefecture-level land use plans. Yet, the policy of lower-limit urban land per capita in land use plans (represented by the variable DENULL) had not been strictly implemented. This finding corresponds to the argument by Han and Lai (2012) that while there are national guidelines of urban construction land per capita for city master plan, the policy has not been well conformed. For the variable LPRICE, the estimated coefficient was significantly positive, which suggests that higher land value was associated with more urban land expansion as found in the study by Martellozzo et al (2015).

Investment (represented by $A C I N V$ and $M A C I N V$ ) was one major factor significantly influencing urban land expansion between 2000 and 2010. Both the estimated coefficients of ACINV (city-level fixed-asset investment) and MACINV (mean of ACINV) were statistically significant in the model I2. These results suggest that fixed-asset investment contributed to urban land development. Similarly, both the estimated coefficients of $C P O P$ and $M C P O P$ were significantly positive, showing positive influences from population growth on urban expansion at the city and provincial levels.

\subsection{Impact from the preservation quota policy}

The estimation results show that the variable $I P Q$ was statistically significant at the $5 \%$ level and possessed negative effects in models of P1, P2, LP, I1 and I2 (see Table 3). The coefficients of the variable $I P Q$ in $\mathrm{P} 1, \mathrm{P} 2, \mathrm{I} 1$, and $\mathrm{I} 2$ ranged from -3.275 to -3.986 , which suggests that the role of prime farmland preservation in influencing urban expansion was relatively robust. The coefficient of the variable $I P Q$ in Model I2 was -3.564 , which indicates that the increase of one unit in $I P Q$ led to about the decrease of 3.564 units in the urban land expansion. That is, in the period of 2000 to 2010 if prime farmland preservation ratio increased 
from $86 \%$ to $87 \%$, the urban expansion would reduce about $3.6 \mathrm{~km}^{2}$ on average. The mean value for the dependent variable is 180.206 , which means that cities expanded approximately $180 \mathrm{~km}^{2}$ on average from 2000 to 2010 . Compared with the mean of the dependent variable (180.206), the coefficient of the variable $I P Q(-3.564)$ is relatively small. It is thus concluded that the policy of prime farmland preservation quota had limited impact on expansion of prefectural-level cities. The top-down land use planning system and the implementation practice account for the finding that the farmland preservation policy had limited effect on urban land expansion of prefecture-level and above prefecture-level cities from 2000 to 2010.

First, the allocation of prime preservation quotas in the prefecture- and lower-level land use plans essentially undermined the effect of the prime farmland quota policy on urban expansion. As mentioned above, farmland is classified into prime farmland and ordinary farmland; any conversion of prime farmland to non-agricultural use needs permission from the State Council. A smaller quota and ratio of prime farmland preservation means less restriction on non-agricultural land development over farmland. Land planning is a hierarchical system in China and higher-level governments have authority in allocating land use quota to their lowlevel governments (Lu and Wang 2020a). As there lacked a top-down guideline for prefectural governments to allocate prime farmland preservation quotas to lower-level governments $(\mathrm{Lu}$ and Wang 2020a), it was common for prefecture-level land use plans to allocate a zero quota or a small quota of prime farmland preservation to the district with a high chance of urban land expansion; most of the quotas could be allocated to the counties far away from core urban areas. For instance, all 2,783 ha of farmland in the "urban district" was classified as ordinary farmland by the Handan Municipal Comprehensive Land Use Plan for 1997-2010 (Lu 2001). Such an approach of allocating prime preservation quotas can make prefectural-level land use plans meet requirements of higher-level plans on prime farmland preservation quotas, as well as avoid the potential limit of prime farmland preservation zones and quotas on urban expansion. Generally, the allocation of prime farmland preservation quotas in the top-down planning system was prefectural-level city favored. Land use plan needed approval from central government and provincial governments; some prefectural governments could be authorized the rights to approve township-level land use plan and plan modification (SCNPC 1998). This has made prefectural governments probably adjusted the boundary of prime farmland protection zones to relieve the limit from prime farmland preservation on urban expansion. Since 2007, the central government has intensified its inspection and supervision on local governments' farmland protection (Zhong et al. 2017), which could have delivered certain impact on slowing urban expansion.

Second, the efficacy of a policy depends on monitoring and implementation. Although the capability of the Ministry of Land and Resources (MLR) to monitor land use change, especially urban expansion, has been gradually strengthened since the end of the 1990s (Zhong 
et al. 2017), the ability to monitor the change of prime farmland was not substantially improved until 2011. Local governments have been required to annually report the area of farmland to their upper-level governments through an annual land use change survey (Zhong et al. 2017), however there was no such requirement for prime farmland before 2011. The MLR lacked the GIS database on local land use plans (Zhong et al. 2017), and was not able to distinguish prime farmland from ordinary farmland that can be converted to non-agricultural use. It was thus difficult for the MLR to monitor whether the farmland converted to non-agricultural use accorded with the requirement of preservation quotas before 2011. In this case, local governments could adjust prime farmland zones to meet their demand for urban land expansion at their discretion, and it was reported that they had developed many means to bypass the regulations on prime farmland conversion to non-agricultural use (Supervisor of State Land 2008; Wang 2005). Unlike the implementation of farmland conversion quotas, there was no annual implementation assessment on prime farmland preservation quotas, but only a 5-year assessment that began in 2011 (MLR et al. 2011). The insufficient capacity of monitoring prime farmland use change and lack of assessment on policy implementation strongly weakened the potential effects of the prime farmland preservation quota policy embedded in the top-down plans on constraining urban land expansion.

\subsection{Impact from the conversion quota policy}

The estimation results show that the variable $I C Q$ was statistically significant. The estimated coefficients of variable ICQ in I1 and I 2 were significant at the $10 \%$ level and they were statistically significant at the 5\% level in P1 and P2. The absolute coefficients of variable $I C Q$ in $\mathrm{P} 1$ and $\mathrm{P} 2$ were larger those in I1 and $\mathrm{I} 2$ (see Table 3). The estimated coefficient of $I C Q$ was -6.646 in the model $\mathrm{I} 2$, which can be interpreted as one unit increase in ICQ leading to about $6.6 \mathrm{~km}^{2}$ decrease in the urban land expansion. The average elasticity can be calculated by using the estimated coefficients, mean of the dependent variable and mean of the variable $I C Q$. The average elasticity value for $I C Q$ is -0.041 in the model $\mathrm{I} 2$, which suggests that one percent increase in ICQ led to about 0.04 percent decrease in urban land expansion. Although the variable $I C Q$ was statistically significant, the average elasticity value for the variable $I C Q$ was small, demonstrating that the change of ICQ had limited influence on the dependent variable despite the estimated coefficients being statistically significant.

The limited effect of the conversion quota policy on controlling urban land expansion of prefecture-level and above prefecture-level cities, to some extent, echoes the limited effectiveness of the farmland protection policy in reducing farmland loss and conversion to non-agricultural use claimed by some of the previous literature (Yue, Liu, and Fan 2013). The effectiveness of farmland preservation policies depends not only on local environmental and socio-economic conditions, but also on the governance and planning system under wider national and regional contexts. Various explanations were proposed for the ineffectiveness of 
the farmland protection policy, including local governments' role in oversupplying farmland conversion (Tan et al. 2011) and local governments' strategy to bypass the central government's oversight (Yew 2011). For the limited effect of the conversion quota policy found in the present study, the following reasons may provide explanation.

Firstly, the allocation of farmland conversion quotas via the top-down planning system is prefecture-level city-biased. For instance, the "Zhejiang Province General Land Use Plan for 1997-2010" allocated about $70 \%$ of its $183.4 \mathrm{~km}^{2}$ quota of farmland conversion for urban use to prefecture-level cities even though it was projected that only about $62 \%$ of the increase in urban population would occur in prefecture-level cities. These cities faced less strict restrictions imposed by the conversion quota; they had larger amounts of fixed-assets investment and the change of GDP.

Secondly, the decoupling of annual quotas and land use planned quotas undermined the controlling effects of planning quotas on urban land expansion. The system of annual quotas was designed as a tool to implement general land use plans, the quotas of which should determine the annual quotas (Zhong et al. 2017). However, there has been significant decoupling of annual quotas and land use plan quotas. As Table 4 (A/B) shows, the total permitted farmland conversion areas between 1998 and 2010 for 20 provincial-level regions (out of 31) are larger than the quotas that were allocated by the National General Land Use Plan for 1997-2010. The decoupling did not only occur at the provincial level, but also at other levels. Besides the decoupling between annual quotas and land use planned quotas, the inannual quotas and actual farmland conversion were not consistent. It can be concluded that the top-down and quota-centered planning system has been faced with a series of challenges in planning implementation.

Table 4 Annual quotas, planned quotas and farmland conversions

\begin{tabular}{lrrrrrr}
\hline Region & A & B & A/B & C & C-B & D \\
\hline Beijing & 2.49 & 2.00 & 1.25 & 4.71 & 2.71 & 1.33 \\
Tianjin & 2.96 & 1.67 & 1.78 & 3.76 & 2.09 & 1.47 \\
Hebei & 8.37 & 9.33 & 0.90 & 11.89 & 2.56 & 4.67 \\
Shanxi & 5.54 & 5.60 & 0.99 & 5.95 & 0.35 & 3.60 \\
Inner & 2.65 & 4.33 & 0.61 & 3.81 & -0.52 & 2.27 \\
Mongolia & & & & & & \\
Liaoning & 8.36 & 6.13 & 1.36 & 6.59 & 0.45 & 3.27 \\
\hline
\end{tabular}




\begin{tabular}{|c|c|c|c|c|c|c|}
\hline Jilin & 4.08 & 3.33 & 1.22 & 3.04 & -0.30 & 2.67 \\
\hline Heilongjiang & 6.11 & 7.33 & 0.83 & 3.92 & -3.41 & 3.20 \\
\hline Shanghai & 6.05 & 2.53 & 2.39 & 6.75 & 4.22 & 1.60 \\
\hline Jiangsu & 18.07 & 10.67 & 1.69 & 23.46 & 12.79 & 6.00 \\
\hline Zhejiang & 13.41 & 6.67 & 2.01 & 19.79 & 13.12 & 5.33 \\
\hline Anhui & 9.54 & 8.67 & 1.10 & 8.67 & 0.01 & 5.07 \\
\hline Fujian & 7.44 & 4.67 & 1.59 & 5.76 & 1.09 & 2.87 \\
\hline Jiangxi & 7.88 & 4.33 & 1.82 & 5.47 & 1.14 & 3.20 \\
\hline Shandong & 14.61 & 11.33 & 1.29 & 22.13 & 10.80 & 6.33 \\
\hline Henan & 11.85 & 11.20 & 1.06 & 12.22 & 1.02 & 6.33 \\
\hline Hubei & 7.76 & 9.67 & 0.80 & 6.08 & -3.58 & 4.47 \\
\hline Hunan & 7.84 & 7.00 & 1.12 & 4.92 & -2.08 & 3.33 \\
\hline Guangdong & 6.26 & 8.00 & 0.78 & 7.46 & -0.54 & 3.67 \\
\hline Guangxi & 5.66 & 5.60 & 1.01 & 5.48 & -0.12 & 4.00 \\
\hline Hainan & 0.59 & 1.07 & 0.55 & 0.34 & -0.73 & 0.93 \\
\hline Chongqing & 8.59 & 4.00 & 2.15 & 5.44 & 1.44 & 2.73 \\
\hline Sichuan & 8.18 & 10.40 & 0.79 & 9.29 & -1.11 & 4.80 \\
\hline Guizhou & 5.98 & 3.33 & 1.79 & 4.24 & 0.91 & 3.20 \\
\hline Yunnan & 7.08 & 5.60 & 1.26 & 6.97 & 1.37 & 3.60 \\
\hline Tibet & 0.70 & 0.27 & 2.64 & 0.30 & 0.03 & 0.20 \\
\hline Shaanxi & 6.10 & 5.60 & 1.09 & 4.91 & -0.69 & 3.60 \\
\hline Gansu & 2.14 & 2.80 & 0.77 & 1.82 & -0.98 & 1.87 \\
\hline Qinghai & 0.83 & 0.93 & 0.89 & 0.91 & -0.02 & 0.67 \\
\hline Ningxia & 1.68 & 0.93 & 1.80 & 1.52 & 0.59 & 1.07 \\
\hline
\end{tabular}




\begin{tabular}{lllllll}
\hline Xinjiang & 3.26 & 6.07 & 0.54 & 2.50 & -3.56 & 3.14
\end{tabular}

Note: A denotes the area of farmland permitted to be converted to non-agricultural use between 1998 and $2010\left(10^{4} \mathrm{ha}\right), \mathrm{B}$ is the farmland conversion quota for 1997-2010 (10 $\left.\mathrm{ha}\right)$, C displays the area of farmland converted to non-agricultural use from 1999 to 2008 (10 $\left.{ }^{4} \mathrm{ha}\right)$, and D represents the farmland conversion quota for 2006-2010 under the National General Land Use Plan for 2006-2020 (10 ha).

Source: MLR (2000-2006), MLR (2007-2012).

Thirdly, incorporating some converted farmland that does not conform to land use plans into the new planning quota is another factor that undermined the effectiveness of the conversion quota policy on restricting urban land expansion. The preparation of the National General Land Use Plan for 2006-2020 was initiated in 2004 (MLR 2004). The State Council authorized the National General Land Use Plan for 2006-2020 in 2008 (State Council of China 2008). As shown in Table 4 (C-B), 17 provincial-level regions were allocated additional quotas of farmland conversion for the period of 2006-2010; the total areas of farmland conversion between 1999 and 2008 for these regions were even larger than the quotas allocated to them by the National General Land Use Plan for 1997-2010. Incorporating the inconsistent part of the quota into a new plan is not unique and has been frequently noticed by researchers. For instance, a study of land use plan implementation revealed the incorporation of nonconforming development in Israel, which led to the ineffectiveness of its comprehensive land use plan (Vyn 2012).

Drawing on the discussions above, this study concludes that the top-down land use planning policies had very limited effects on containing urban land expansion from 2000 to 2010. During this period, China experienced substantial change in its economy and population with the urbanization level increasing from 36.2 percent in 2000 to 49.7 percent in 2010 (NBS 2020). The rapid change in population and economy brought a growing demand for construction land, which further stimulated local governments to bypass the influence of farmland preservation policies on urban land expansion. This tendency of sidestepping the legal framework at the national level also happened in other contexts such as France and Rome due to the development pressure at the local level (Perrin et al. 2018). Increasing urban population and households' income has increased food demand while rural depopulation has led to farmland abandonment ( $\mathrm{Li}$ and $\mathrm{Li}$ 2017). All these issues call for more effective measures to protect farmland and concerted efforts from multiple policy sectors and multilevel governments via a strategic and consistent spatial planning approach. In China, the central government cares more about food security and farmland protection while local governments focus on their own economic development (Wang et al. 2010). For this reason, there is a need 
to legally binding policy instruments at multiple levels from national to local (Oliveira, Leuthard, and Tobias 2019). A certain degree of flexibility in planning implementation at the local level can correspond to local differentiations while timely and frequent reviews of policy instruments and implementation at multiple levels are crucial. To make adaptative planning and implementation, there is a need to intensify land use monitoring, especially the change of farmland. Furthermore, it is suggested to increase farmland utilization and labor productivity via different approaches such as land consolidation to reduce fragmentation (Cheng et al. 2015).

\section{Conclusion}

Due to China's unique development mode and institutional context, how farmland preservation policies influence urban expansion and to what extent are extraordinarily complex. This study contributes to existing scholarship by examining the impact of two principal farmland protection policies embedded in China's top-down land use planning: the policy of the farmland conversion quota and the policy of the prime farmland preservation quota. Going beyond other empirical studies at the local scale, this study used a multi-level modelling approach to unfold the underlying factors of urban expansion by drawing upon the large-scale data of prefecture-level and above prefecture-level cities in China. A comprehensive understanding of the underlying relationships between farmland protection policies and urban expansion can shed light on relevant policymaking. The method that we adopted to measure farmland protection policies is the intensity of farmland protection policies via two ratio indicators rather than the dummy variable in most studies. By controlling different types of variables, this research provides a nuanced understanding of the impacts from the two policies. From a methodological perspective, this study adopts more robust models by analyzing largescale data from a multi-level perspective.

The results suggest that the implementation of the farmland conversion quota and the prime farmland preservation quota had limited effects on controlling urban land expansion of prefecture-level and above prefecture-level cities in China during the period of 2000 to 2010. The increase in the intensity of prime farmland preservation (measured as the ratio of prime farmland preservation) resulted in limited decrease in urban land expansion. The increase in the intensity of the conversion quota policy slightly reduced urban land expansion. The limited effects of both the preservation quota policy and the conversion quota policy are attributed to two main gaps. First, there existed a gap of political willingness to protect farmland between the central and local governments. With different political goals, the priority for the local government was to obtain more land for economic development while the central government aimed at ensuring food security at the national level. Without a coherent objective, local governments were always attempting to bypass the regulations. What is more, there was a gap between the actual capacity of policy implementation and the expected capacity required to 
achieve policy goals. The capacity deficit of monitoring policy implementation and several critical issues embedded in the top town land use planning system brought about the limited policy effect, including the prefecture-level city-biased allocation of preservation and conversion quotas, limited capability of monitoring farmland changes especially prime farmland, the decoupling between annual conversion quotas and land use planned quotas, and incorporating the inconsistent farmland conversion quota into new plans. Scrutinizing the issue, the lack of a clearly defined guidance for policy implementation and the insufficient capability to monitor policy implementation play a significant role. Due to limited locational information on prime farmland, the central government and provincial governments found it almost impossible to timely and widely assess whether certain urban expansion took place on prime farmland across the country during 2000 to 2010. Prefecture-level and above prefecture-level cities could disproportionately allocate a greater quota of prime farmland preservation to the counties or districts far away from city-proper and purposely assign the farmland close to builtup areas as ordinary rather than prime farmland in the planning process.

The main challenges for improving top-down and quota-based planning and implementation are rooted in the planning system which involves the hierarchical allocation of conversion quotas, the horizontal allocation of conversion quotas amongst administrative regions at the same level, and the approach taken to translating planned quotas into annual quotas. Due to the complexity of the plan-making and implementation process, it is crucial to develop a coherent and integral spatial plan, build a centralized and highly efficient system of planning review (plan assessment before authorization), and foster a monitoring system of plan implementation. The planning process must consider different scenarios and include more detailed implementation rules. Timely and frequent reviews of policy implementation can further alleviate attempts to circumvent policy implementation. From a policy perspective, one important contribution of this paper is to reveal how the two gaps mentioned above undermined the effect of top-down policies and to suggest a potential pathway for improving the effect of policies to control urban expansion by reducing the capacity gap of policy implementation. Despite China's unique context, the lessons learnt from this study, particularly a call for coherent and integrative planning and implementation, are relevant to other contexts which are experiencing rapid urbanization.

\section{References}

Angel, S., J. Parent, and D. L. Civco. 2012. "The fragmentation of urban landscapes: global evidence of a key attribute of the spatial structure of cities, 1990-2000." Environment and Urbanization 24 (1):249-83. doi: 10.1177/0956247811433536.

Bai, X. M., J. Chen, and P. J. Shi. 2012. "Landscape Urbanization and Economic Growth in China: Positive Feedbacks and Sustainability Dilemmas." Environmental Science \& Technology 46 (1):132-9. doi: 10.1021/es202329f. 
Bengston, D. N., J. O. Fletcher, and K. C. Nelson. 2004. "Public policies for managing urban growth and protecting open space: policy instruments and lessons learned in the United States." Landscape and Urban Planning 69 (2-3):271-86. doi: 10.1016/j.landurbplan.2003.08.007.

Brinkley, C. 2012. "Evaluating the Benefits of Peri-Urban Agriculture." Journal of Planning Literature 27 (3):259-69. doi: 10.1177/0885412211435172.

Chau, N. H., and W. W. Zhang. 2011. "Harnessing the Forces of Urban Expansion: The Public Economics of Farmland Development Allowances." Land Economics 87 (3):488-507.

Cheng, Liang, Nan Xia, Penghui Jiang, Lishan Zhong, Yuzhe Pian, Yuewei Duan, Qiuhao Huang, and Manchun Li. 2015. "Analysis of farmland fragmentation in China Modernization Demonstration Zone since "Reform and Openness": a case study of South Jiangsu Province." Scientific Reports 5 (1):11797. doi: 10.1038/srep11797.

China Land Surveying and Planning Institute, and Twenty First Centuary Aerospace Technology Co. Ltd. 2015. "Atlas for Remote Sensing of Urban Expansion of Prefecture- and Above Prefecture-level Cities in China." Beijing, China: Geological Publishing House.

Coughlin, R. E. 1991. "Formulating and evaluating agricultural zoning programs." Journal of the American Planning Association 57 (2):183-92. doi: 10.1080/01944369108975486.

Daniels, T. L. 2020. "Assessing the performance of farmland preservation in America's farmland preservation Heartland: A policy review. " Society \& Natural Resources, 33(6): 758-768. doi: 10.1080/08941920.2019.1659893

Deng, X. Z., J. K. Huang, S. Rozelle, and E. Uchida. 2010. "Economic Growth and the Expansion of Urban Land in China." Urban Studies 47 (4):813-43. doi: 10.1177/0042098009349770.

Gao, J. L., Y. D. Wei, W. Chen, and J. L. Chen. 2014. "Economic transition and urban land expansion in Provincial China." Habitat International 44:461-73. doi: 10.1016/j.habitatint.2014.09.002.

Han, Haoying, and Shih-Kung Lai. 2012. "National Land Use Management in China: An Analytical Framework." Journal of Urban Management 1 (1):3-38. doi: 10.1016/S2226-5856(18)300529.

Huang, D. Q., H. R. Jin, X. S. Zhao, and S. H. Liu. 2015. "Factors Influencing the Conversion of Arable Land to Urban Use and Policy Implications in Beijing, China." Sustainability 7 (1):180-94. doi: $10.3390 /$ su7010180.

Jaeger, W. K. 2013. "Determinants of urban land market outcomes: Evidence from California." Land Use Policy 30 (1):966-73. doi: 10.1016/j.landusepol.2012.02.001.

Jerry, Anthony. 2004. "Do State Growth Management Regulations Reduce Sprawl?" Urban Affairs Review 39 (3):376-97. doi: 10.1177/1078087403257798.

Jiang, L., X. Z. Deng, and K. C. Seto. 2012. "Multi-level modeling of urban expansion and cultivated land conversion for urban hotspot counties in China." Landscape and Urban Planning 108 (24):131-9. doi: 10.1016/j.landurbplan.2012.08.008.

Kuang, Wenhui, Jiyuan Liu, Jinwei Dong, Wenfeng Chi, and Chi Zhang. 2016. "The rapid and massive urban and industrial land expansions in China between 1990 and 2010: A CLUD-based analysis of their trajectories, patterns, and drivers." Landscape and Urban Planning 145:2133. doi: 10.1016/j.landurbplan.2015.10.001.

Leo, Christopher, and Kathryn Anderson. 2006. "Being realistic about urban growth." Journal of Urban Affairs 28 (2):169-89. doi: 10.1111/j.0735-2166.2006.00266.x. 
Li, H., Y. D. Wei, F. H. Liao, and Z. J. Huang. 2015. "Administrative hierarchy and urban land expansion in transitional China." Applied Geography 56:177-86. doi: 10.1016/j.apgeog.2014.11.029.

Li, Shengfa, and Xiubin Li. 2017. "Global understanding of farmland abandonment: A review and prospects." Journal of Geographical Sciences 27 (9):1123-50. doi: 10.1007/s11442-017-14260.

Li, Xiubin. 2011. "Farmland grabs by urban sprawl and their impacts on peasants' livelihood in China : an overview." Paper presented at International Conference on Global Land Grabbing, University of Sussex, UK, April 6-8.

Long, H. L. 2014. "Land use policy in China: Introduction." Land Use Policy 40:1-5. doi: 10.1016/j.landusepol.2014.03.006.

Lu, S. H., and H. Wang. 2020a. "Distributive politics in China: Regional favouritism and expansion of construction land." Urban Studies 57 (8):1600-19. doi: 10.1177/0042098019835677. 2020b. "Local economic structure, regional competition and the formation of industrial land price in China: Combining evidence from process tracing with quantitative results." Land Use Policy 97. doi: 10.1016/j.landusepol.2020.104704.

Lu, Xinshe. 2001. Quanguo Tudi Liyong Zongtiguihua [National General Land Use Planning (19972010)]. 1 ed. Beijing, China: China Land Press.

Luo, Jun, and Y. H. Dennis Wei. 2009. "Modeling spatial variations of urban growth patterns in Chinese cities: The case of Nanjing." Landscape and Urban Planning 91 (2):51-64. doi: 10.1016/j.landurbplan.2008.11.010.

Martellozzo, Federico, Navin Ramankutty, Ron J. Hall, David T. Price, Brett Purdy, and Mark A. Friedl. 2015. "Urbanization and the loss of prime farmland: a case study in the Calgary-Edmonton corridor of Alberta." Regional Environmental Change 15 (5):881-93. doi: 10.1007/s10113014-0658-0.

Millward, Hugh. 2006. "Urban containment strategies: A case-study appraisal of plans and policies in Japanese, British, and Canadian cities." Land Use Policy 23 (4):473-85. doi: 10.1016/j.landusepol.2005.02.004.

MLR (Ministry of Land and Resources). 2000-2006. China Land and Resources Almanac/Guotu Ziyuan Nianjian (1999-2005). Beijing, China: Editorial Office of China Land and Resources Almanac. 2007-2012. China Land and Resources Statistical Yearbook/Guotu Ziyuan Tongji Nianjian (2006-2011). Beijing, China: Geological Publishing House.

MLR (Ministry of Land and Resources), MOA (Ministry of Agriculture), MOS (Ministry of Supervision), NAO (National Audit Office ), and NSB (National Statistics Bureau). 2011. "Circular on Assessing Province-level Government's Target Responsibility of Farmland Protection for the Period of 2006-2010." http://www.mlr.gov.cn/zwgk/zytz/201107/t20110729_912233.htm.

MLR(Ministry of Land and Resources). 2004. "Circular on Carrying out Implementation of General Land Use Plan and Investigation on Plan Revision." http://hd.bjgtj.gov.cn/tabid/4210/InfoID/73491/frtid/4198/Default.aspx.

NBS (National Bureau of Statistics). 2002-2012. "China City Statistical Yearbook." Beijing, China: China Statistics Press. 
. 2020. "National Data." Beijing, China: National Bureau of Statistics of China. https://data.stats.gov.cn/.

Oliveira, E., J. Leuthard, and S. Tobias. 2019. "Spatial planning instruments for cropland protection in Western European countries." Land Use Policy 87. doi: 10.1016/j.landusepol.2019.104031.

Overmars, Koen P., and Peter H. Verburg. 2006. "Multilevel modelling of land use from field to village level in the Philippines." Agricultural Systems 89 (2-3):435-56. doi: 10.1016/j.agsy.2005.10.006.

Paulsen, K. 2013. "The Effects of Growth Management on the Spatial Extent of Urban Development, Revisited." Land Economics 89 (2):193-210.

Peng, Wenfu, Guangjie Wang, Jieming Zhou, Jingfeng Zhao, and Cunjian Yang. 2015. "Studies on the temporal and spatial variations of urban expansion in Chengdu, western China, from 1978 to 2010." Sustainable Cities and Society 17:141-50. doi: 10.1016/j.scs.2015.03.004.

Perrin, C., B. Nougaredes, L. Sini, P. Branduini, and L. Salvati. 2018. "Governance changes in periurban farmland protection following decentralisation: A comparison between Montpellier (France) and Rome (Italy)." Land Use Policy 70:535-46. doi: 10.1016/j.landusepol.2017.09.027.

Rabe-Hesketh, S., and A. Skrondal. 2012. Multilevel and Longitudinal Modeling Using Stata, Volumes I and II, Third Edition: Taylor \& Francis.

SC (State Council). 1998. "Basic Farmland Protection Regulation." In, edited by The State Council.

1999. "National General Land Use Plan (1997-2010)." http://www.mlr.gov.cn/zwgk/flfg/tdglflfg/200406/t20040625_570370.htm.

SCNPC (Standing Committee of National People's Congress). 1998. "Land Administration Law of China." http://www.zhb.gov.cn/ztbd/rdzl/2010sdn/zcfg/201001/t20100113_184226.htm.

Seto, Karen C., Michail Fragkias, Burak Gueneralp, and Michael K. Reilly. 2011. "A Meta-Analysis of Global Urban Land Expansion." Plos One 6 (8). doi: 10.1371/journal.pone.0023777.

State Council of China. 2008. "Circular on Issuing National General Land Use Plan(2006-2020)." In. Supervisor of State Land. 2008. "Guojia Tudi Ducha Gonggao (Diyi Hao) [Announcement of the Supervisor of State Land (NO. 1)]." http://www.mlr.gov.cn/zwgk/zytz/200805/t20080509_672644.htm..

Tan, R., F. T. Qu, N. Heerink, and E. Mettepenningen. 2011. "Rural to urban land conversion in China - How large is the over-conversion and what are its welfare implications?" China Economic Review 22 (4):474-84. doi: 10.1016/j.chieco.2011.07.013.

Towe, Charles A, Cynthia J Nickerson, and Nancy Bockstael. 2008. "An empirical examination of the timing of land conversions in the presence of farmland preservation programs." American Journal of Agricultural Economics 90 (3):613-26. doi: 10.1111/j.1467-8276.2007.01131.x

Vyn, R. J. 2012. "Examining for Evidence of the Leapfrog Effect in the Context of Strict Agricultural Zoning." Land Economics 88 (3):457-77. doi: 10.3368/le.88.3.457.

Wang, H., R. Tao, L. L. Wang, and F. B. Su. 2010. "Farmland preservation and land development rights trading in Zhejiang, China." Habitat International 34 (4):454-63. doi: 10.1016/j.habitatint.2009.12.004.

Wang, Yonghong. "The prime farmland protection is looking blue." http://www.mlr.gov.cn/xwdt/jrxw/200510/t20051024 640725.htm. 
Woo, Myungje, and Jean-Michel Guldmann. 2014. "Urban containment policies and urban growth." Review of. International Journal of Urban Sciences 18 (3):309-26. doi: 10.1080/12265934.2014.893198.

Wu, F. 2015. Planning for Growth: Urban and Regional Planning in China: Taylor \& Francis.

Wu, Kai-ya, and Hao Zhang. 2012. "Land use dynamics, built-up land expansion patterns, and driving forces analysis of the fast-growing Hangzhou metropolitan area, eastern China (1978-2008)." Applied Geography 34:137-45. doi: 10.1016/j.apgeog.2011.11.006.

Yew, C. P. 2011. "Explaining Land Use Change in a Guangdong County: The Supply Side of the Story." China Quarterly (207):626-48. doi: 10.1017/s0305741011000683.

York, A. M., and D. K. Munroe. 2010. "Urban encroachment, forest regrowth and land-use institutions: Does zoning matter?" Land Use Policy 27 (2):471-9. doi: 10.1016/j.landusepol.2009.06.007.

Yue, Wenze, Yong Liu, and Peilei Fan. 2013. "Measuring urban sprawl and its drivers in large Chinese cities: The case of Hangzhou." Land Use Policy 31:358-70. doi: 10.1016/j.landusepol.2012.07.018.

Zhao, Pengjun. 2011. "Managing urban growth in a transforming China: Evidence from Beijing." Land Use Policy 28 (1):96-109. doi: 10.1016/j.landusepol.2010.05.004.

Zhong, Taiyang, Bruce Mitchell, Steffanie Scott, Xianjin Huang, Yi Li, and Xiao Lu. 2017. "Growing centralization in China's farmland protection policy in response to policy failure and related upward-extending unwillingness to protect farmland since 1978." Environment and Planning C: Politics and Space 35 (6):1075-97. doi: 10.1177/0263774X16682958.

Zhou, Y., X. J. Huang, Y. Chen, T. Y. Zhong, G. L. Xu, J. L. He, Y. T. Xu, and H. Meng. 2017. "The effect of land use planning (2006-2020) on construction land growth in China." Cities 68:3747. doi: 10.1016/j.cities.2017.04.014. 